\title{
Skilled migration and development: portable communicative resources for transnational work
}

\author{
Suresh Canagarajah
}

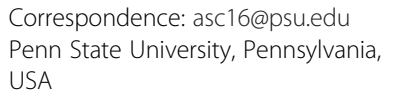

Correspondence: asc16@psu.edu Penn State University, Pennsylvania, USA

\begin{abstract}
As interest grows on the value of skilled migration for development, scholars and policy makers are addressing the portable resources migrants need for professional success and development contributions in home and host communities. Neoliberal orientations to human capital emphasize scripted communication in a uniform language for efficiency. Lingua franca English thus gains importance in immigration policies in host communities and educational policies in home countries. The interview-based study with African skilled migrants reported in this article points to a different answer. The narratives reveal the value of negotiating different varieties of English and diverse languages in professional and development contexts. The interviewees are able to adopt such an orientation because they have developed certain dispositions to engage with language diversity in their multilingual social backgrounds. This paper argues for treating such dispositions as a more beneficial portable resource as it enables migrants to negotiate diversity and expand their repertoires for transnational work and development.
\end{abstract}

As globalization and development become interconnected, there is considerable interest in the language resources that facilitate these twin processes. Nowhere is this inquiry more relevant than in the area of skilled migration. The migration of highly educated professionals from the developing South to the developed North used to be perceived as causing "brain drain" in the 1960's see (Bhagwati 1976). It is now being treated as a win-win situation for both the developing and developed communities and redefined as "brain gain" see (Kuznetsov, 2006). The knowledge, skills, and resources migrants bring from their home communities contribute to development beyond the receiving countries. While enhancing technological and economic advancement in the developed communities, skilled migrants also contribute to the development of their home communities. In many cases, the benefits go beyond sending countries, as skilled migrants form affiliations with diverse other countries and develop diasporic identities beyond the nation-state framework. The following benefits have been widely documented for developing countries: skilled migrants send back remittances, share their skills and knowledge to help in education and industrial development, outsource work from the North to companies in the South, and invest in new development initiatives see (Kuznetsov 2006; Mercer et al., 2008). There is considerable interest now on developing the human capital required to facilitate this productive migration/development nexus. Human-capital perspectives theorize the cultural, communicative, and intellectual resources that enable skilled migrants to engage in such multifaceted development

(c) 2013 Canagarajah; licensee Springer. This is an Open Access article distributed under the terms of the Creative Commons Attribution License (http://creativecommons.org/licenses/by/2.0), which permits unrestricted use, distribution, and reproduction in any medium, provided the original work is properly cited. 
activity. Language is an important portable resource that has received much attention. There are tremendous policy implications behind these discourses on portable language resources, as policy makers in both sending and receiving countries are emphasizing the required languages and communicative practices in their education and immigration planning. In this article, I draw from narratives of skilled migrants from an interview-based study to broaden the perspective on the types of communicative resources required for migration and development $\mathrm{a}^{\mathrm{a}}$.

\section{Dominant perspectives on portable resources}

There are two dominant orientations to language as a portable human capital in current scholarly and policy discussions. On the one hand, policy makers consider it important that migrant workers know the language of the host community in order to be successful. It is widely assumed that those who are proficient in the dominant language of the receiving countries tend to adapt well to local social life, get better employment, and become economically more successful. As Williams \& Balaz (2008) point out, "The classic human-capital perspective suggests that immigrants tend to adapt to their host countries via accumulating human capital. A critical element of human capital is fluency in the host country's language, which mediates their integration into that country's labor market" (p.29).

The second related perspective derives from the neoliberal ideological orientation (Duchene \& Heller, 2012; Piller \& Cho, 2013). This perspective is based on the resurgence of market fundamentalism, affirming the benefits of corporatization and free trade at transnational level. According to this perspective, the ability of knowledge workers to cross borders and enhance production requires flexibility in communication, values, and resources. The way to achieve this flexibility, according to this perspective, is through standardized skills and resources which are easily adaptable everywhere. Heller \& Duchene (2012) explain the rationale for this orientation thus: "Global management, in its search for taylorist modes of regularization carried through from modern economic activities, often also looks for ways to technicize and standardize linguistic regulation techniques. These techniques construct language as a technical skill, decoupled from authenticity" (p. 10). When communication is technicized, as in the scripted communication workers are expected to adopt in workplaces, their identities are considered irrelevant. Hence it is "decoupled from authenticity." An additional way to achieve standardization is through lingua franca English. If people from diverse countries learnt English, they can move with flexibility to other countries for education, work, and development, it is assumed. Since English is the dominant language in some of the developed countries migrants travel to for education and employment (i.e., UK, USA, Canada, and Australia), this language also gains value according to the nationstate based human-capital perspectives described above.

The power of lingua franca English is sustained by the immigration policies of receiving countries and the educational policies of sending countries. In countries such as Canada, New Zealand, United Kingdom, and Australia, a high score in IELTS (International English Language Testing Systems) is required to qualify as a skilled migrant (see http://bandscore.ielts.org/government.aspx). In Australia, for example, skilled migrants earn 20 points for passing on the highest band in IELTS, but 15 points for 8-10 years of work experience in Australia or their home country. This requirement shows 
the high value placed on English proficiency for skilled migration. The international popularity of tests like IELTS also show that language competence is so standardized that even the tests relating to assessing proficiency in English are becoming uniform for all countries. A common standard of measurement will presumably allow for regularization of language as the portable communicative resource. Perhaps motivated by such immigration requirements, and of course influenced by related human-capital and neoliberal discourses, many sending countries are providing an important place for the teaching of English in their education system. What Martin (2012) says about Philippines is true of many other developing countries:

The Philippine government's formula for economic success has become painfully simplistic: English equals money. Whether Filipino graduates are capable of critical and creative thinking, or have acquired basic life skills other than language skills, does not seem to be a major concern. The Philippine government's language policies seem to be fixated on English alone (p. 194).

The obsession with English is so strong that education is not sufficiently rounded as to focus on relevant thinking and life skills. Ironically, the previous postcolonial drive to develop local languages and cultural resources in many developing countries has been overshadowed by the neoliberal turn that emphasizes uniform languages and cultures see also (Lorente 2012, for Philippines; and Piller \& Cho, 2013, for South Korea). In addition to the emphasis on English in state-run schools, there is also a stampede to acquire "global English" in the private/commercial sector as evidenced by the mushrooming tutories all over developing countries.

The new focus on lingua franca English for development has been bolstered by research and scholarship in certain quarters. There is a preponderance of demographic studies that show a correlation between those who are proficient in the dominant language of the host country and the economic success of the migrant see (Adsera \& Pytlikova, 2010; Bleakley \& Chin, 2004; Chiswick \& Miller, 1995, 2002, 2007; Dustmann \& van Soest 2002; Dustmann \& Fabbri, 2003; Dustmann 1994). These studies show that those who are proficient in English tend to be better employed. They also show that those who are from countries which provide an important place for English in their education or society (such as former British colonies, India or Singapore) are better employed, while those from countries which traditionally lack English proficiency (i.e., East Asian or East European countries) tend to be less so. These demographic and quantitative studies, however, miss a lot of information. They don't explore the languages that are actually involved in professional communication (i.e., though subjects might be proficient in English, is that the only language they are using in their workplace?); the attitudes of the migrants towards the languages they use (i.e., though subjects might be proficient in English, do they value it over their other languages?); and the other forms of social capital that languages may or may not provide access to (i.e., is English the critical factor or the social connections and professional status subjects may enjoy?).

\section{Research context}

In this report of a qualitative study, I re-examine the dominant scholarly and policy assumptions on globalization, development, and the role of language. The data in this 
article come from the project "Skilled Migration and Global English: Language, Development, and the African Professional" carried out between February 2010 to $2011^{\mathrm{b}}$. A multidisciplinary group of scholars from the following universities collaborated with me in obtaining data: Universities of Bristol, Leeds, and York (UK); University of Sydney (Australia); University of Cape Town (South Africa), and the Universities of Wisconsin and Washington (USA). The focus of our inquiry was how language skills facilitate success for skilled migrants in their professions in host communities and, in turn, influence productive contributions for development activities.

This study focused on different destination countries (USA, UK, Australia, and South Africa) where English is the dominant national language. The interview subjects come from sub-Saharan Africa. We chose to focus on African skilled migrants, as studies show that they are less organized than migrants from other developing regions and countries see (Kuznetsov 2006). Skilled professionals are defined as those holding a baccalaureate or comparable educational degree, and working in a profession that requires credentialized skills. The informants come from a range of professions, especially from the fields of education, health care, and management. For data gathering purposes, field workers focused on urban settings close to their universities. The study involved a total of 66 participants, though the transcripts of only 60 are used in the analysis as the others had to be rejected for various procedural reasons. The objective during data collection was to obtain in-depth narratives and opinions on the ways skilled migrants negotiate language differences in inter-community relations. The research method involved face-to-face, telephone, and email interviews. All face-to-face and telephone interviews were audio-recorded and transcribed. Each interview ran for around 45 to 90 minutes. Of the 60 participants included, 21 were females. They come from the following countries: Cameroon, Democratic Republic of Congo, Ethiopia, Ghana, Malawi, Nigeria, Sierra Leon, Sudan, Tanzania, Uganda, and Zimbabwe. Though I was open to the fact that skilled migration is short term and transitory, most of the subjects in the study had been working in the host country for $2-5$ years.

The semi-structured interview based on 18 questions, adjusted minimally for context, focused on eliciting narratives on five over-riding themes of importance for this project:

1. How does English shape the flow of skilled migrants and trajectories of migration?

2. In what ways does English shape the levels of success of skilled migrants?

3. How do skilled migrants negotiate their different English varieties with those in the host communities?

4. How do skilled migrants negotiate the tensions in identity deriving from different languages in relationships among themselves and with other communities?

5. Are there language-related tensions as skilled migrants undertake development efforts in their home countries?

The narratives from the interview data were then coded, along the principles of grounded theory see (Clarke 2005; Birks \& Mills, 2011) to identify the orientations of the subjects to their communicative practices in the contexts of work and development. 


\section{The transnational workplace}

The subjects almost unanimously agreed that English had played a critical role in their pathways to professional migration. Their proficiency in English, often excellently developed by the educational systems in their own countries, had shaped their interests in migrating to English-dominant host communities, facilitated their entry into the country by earning them points for skilled migration, helped them gain advanced professional and academic training after migration, and qualified them for coveted jobs inaccessible to those who were not competent in English. Others went on to narrate how their proficiency in English was critical for their status in their professions. They could be penalized or they might stagnate in their employment for signs of unproficiency in English. These findings were not surprising. They show the institutional and policy importance of English. The power of neoliberal discourses explains why entry into countries and professions depends on a proficiency in English. However, the subjects went to narrate how their everyday work and development efforts were more linguistically diverse. In this sense, there emerged a slight tension between policy and practice. I focus on the everyday communicative experiences and attitudes of skilled migrants, which are missing in the current scholarship on the migration/development nexus.

Even if the physical location of their work is in a dominantly English-speaking setting (i.e., UK or USA), the subjects found that the work involved multinational or transnational engagement, requiring interactions in diverse varieties of English and/or diverse languages. This finding shouldn't be surprising as the nature of globalization is such that it is simplistic to assume that professional interactions today are limited to local or homogeneous domains.

To begin with, many subjects mentioned that their interactions in their workplace often involved subjects from their own countries. For example, there was a large group of health care professionals from Zambia in Leeds. They collaborated in "covering for" each other (i.e., overcoming the linguistic and communicative requirements by helping each other beat the system). LA went on to say: "I have good strong relationships with other Zimbabwean nurses that work in Leeds. We are friends because we come from same country. We may speak different languages, but we help one another at work. [. . .] It's not like the white nurses can write like the other Zimbabweans who passed from home, they make mistakes like me but they cover for each other, so Zimbabweans are covering for me, helping me, just like white nurses and Asian nurses cover for each other." It is also clear from LA's statement that the Zimbabwean nurses interact with each other in their local languages. Another subject LO mentioned that his interactions with fellow Zimbabweans was always in “Shona and English. It doesn't have any impact, we use both languages simultaneously. We have our own language here in the diaspora, a mixture of English and Shona and people can dip in and out of either language. We all understand English and Shona so there is no bearing whatsoever." It is evident that the mixed language practices typical in their communities (perhaps both in their homelands and in the diaspora) characterize their workplace communication in the host countries.

Others mentioned that most of their interactions were with other multilingual professionals from the African diaspora, which enabled them to negotiate their language differences well. YB, a social worker from Burundi in Bradford (UK), acknowledged that 
in everyday conversations he does face tensions and native speakers complain about his accent. However, he argued that he didn't have problems in his work. As the puzzled interviewer pressed him for an explanation, YB mentioned that his immediate supervisor is from Ghana. The Ghanaian supervisor and the Burundian worker are able to negotiate comprehension and achieve communicative success. We will see the possible strategies they might have used from the other data below.

Similarly NN, a teacher from Zimbabwe in Sheffield, mentioned that many of his coteachers in his school were international, and they all adopted their own varieties of English for communication. He said: "The other guys are from South Africa, India and Trinidad, so it is easy for us to get together really. We speak different English, we speak it differently but we understand each other. We don't need an interpreter, which is good, and over the years we have grown to understand each clearly than maybe was the case at first." He went on to say that since his school was far away from the city and constituted a community of its own, even the "Britons" in the school had developed the ability to understand the international teachers. In a sense, this community had developed a more tolerant and diverse norm for English communication. He said: "I think as a community, we are very united, maybe it's because we are isolated from the other communities and we just have to get along well. It could also be because the majority if not all of us who live here are foreigners." This is a community that has consented to treat each person's English as normative and adapt to their differences. Their common status as foreigners seems to have created the proper attitude to negotiate their language differences amicably.

In the same way that interactions with co-workers is multinational, the subjects' work brought them into contact with clients from different cultural and national backgrounds. These interactions also required a negotiation of diverse dialects ${ }^{C}$ of English. A university professor from Tanzania in Penn State mentioned that her awareness of diversity in English and her familiarity with some of these varieties enabled her to adopt them with her multinational students. She said: "I can if I talk with African Americans, I can talk with them with really about (xxx). With Nigerians, speak pidgin. And so more or less, if I talk with Indians, I do I will try to so that, I'm with the part of that culture. [. . . ] So how do I do it? I'm versatile. I just go with the flow, or I look at the makeup of my class sometimes and I do. They like it sometimes when I talk like them. Anyway, we cruise." She is thus able to establish rapport with her students from diverse backgrounds. She attributed this versatility to her own transitional background--"because of these movements from one place to another, or multiplicity of languages, I don't know." In this sense, she finds her multidialectalism in English an asset for her teaching.

For many subjects, their clientele was also transnational. Though their place of work was located in an English-dominant country, they had to interact with clients from many other countries. LE, an accountant from Zimbabwe in Leeds, explained: "I am beginning to realize that in order to be extra successful, English isn't the only language that I need. French is also quite important because some of our important customers especially in Africa are from Francophone Africa. Thus the people at the pinnacle of my industry are the ones that can't only speak English but speak it in conjunction with another UN language hence my decision to learn French.” AM, a professor in Engineering from Nigeria in Penn State, mentioned that his work in the same university had 
transitioned to more international responsibilities. He is now an administrator, in charge of global relations. In this capacity, he has to travel to diverse countries to recruit students and scholars for the university and facilitate collaboration with foreign universities and institutes. For this mission, MA needed more than American or Nigerian English. He said: "Now I focus on the entire globe so I have very little professional contact with the country [i.e., Nigeria], simply because my responsibility now take me in to, not a such as I used to of course, no I don't. I currently do not engage in a lot of consulting works simply because I don't have time to do consulting, so [. . .] Right now, I can cope with any varieties of English because I deal with people who speak different accents, because I travel all over the world. And when in India, for example, then I'm in China, when I'm in Britain, and so now my ear is tuned towards different accents or what they call accent." It is clear that if MA had been obsessed with mastering American English, he may not have developed the competence to negotiate the diverse dialects he encounters now in his work. It is therefore an asset to his host country institution that MA can work proficiently with diverse varieties of English. A US university is able to accomplish its global mission because of professionals like AM who have such multidialectal competence.

In other cases, the interviewees mentioned that they exercised their own agency and expected even native speaker clients/co-workers to co-construct norms and meanings with them. They didn't consider adopting the dominant local norms (British English in UK, for example) as the preferred option. They considered it important to maintain their voice and identity, considering their professional expertise as more important than superficial markers of their English accent. ET, a physician from Zimbabwe in Sheffield, said in his emailed response: "I think because it is such a professional job, people are prepared to overlook the language issue. They would rather have an excellent physician who speaks little English than see him go to another country e.g. US. Besides, I think the patients wouldn't mind whether the physician who treated them, saved their life, was speaking broken English or fluent English as long as they are good at what they do, that is all that matters. I think medicine and other technically demanding fields don't really need someone to be fluent in English, as long as they can make a diagnosis that is all that matters. It's more like football, Ronaldo didn't speak a word of English, neither does Messi, but they are technically very good at it. Most teams now are composed of footballers from different countries who all speak different languages but they still deliver. That is what medicine is like." Though ET uses derogatory terms like "little English," "broken English" and lack of "fluent English" that smack of deficiency, we have to understand that he is presenting his competence from the perspective of native speakers. His email communication shows fluency, though he will probably display his own accent and idiomatic peculiarities in oral interactions. What gives ET confidence in this agentive stance is his opinion that his professional status and expertise give him a social capital that overrides perceptions of linguistic deficit. It appears that one's status in the knowledge economy is not based on elite varieties of English alone. ET adopts the functional orientation that what should be valued is the professional's ability to perform effectively (i.e., the ability to "deliver") and not puristic norms of linguistic correctness.

ET's desire to maintain his language also suggests an affirmation of one's identity. In a context where neoliberal communication scripts uniform communication and suppresses 
identity for the sake of efficiency and production, our subjects articulated some of the benefits of identity. LM, the professor from Penn State, argued that her multilingualism and diversity of identity enabled her to draw from her multicultural experiences to provide a critical education in an American university. She narrated how she would draw from her identity and background to challenge the limited orientations of American students or textbooks. Furthermore, she articulated how an appreciation of local knowledge from diverse communities might contribute to a richer notion of development: "The good part is, I think as people are starting to realize more and more, that there is something to be learned, that also gives me a hope at least a bit of hope that, that indigenous culture will be taken seriously now more than ever and indigenous knowledge. We have seen that what have you and we have seen that to get to, like to get the herbs from China and other parts of Asia shows that there is acknowledgement, knowing from whichever places, where in the past it may be it wasn't so it's going, it gives me hope in some ways but there's a lot to be done." In this sense, welcoming the multilingual identities of skilled migrants in the workplace might provide access to diverse forms of knowledge and cultural resources they bring with them, enabling them to creatively challenge and reconfigure dominant professional practices.

\section{The transnational development work}

The narratives also reveal that the communication practices involved in development work are more complex than English Only. Development work requires that skilled migrants not only acquire useful knowledge in the receiving countries, but translate and transmit such knowledge effectively in their own communities. Since the local communities in Africa (as in developing communities elsewhere) are multilingual, a knowledge of English alone will not help skilled migrants to perform this service effectively.

In fact, English can sometimes be dysfunctional in the work these subjects have to perform in their local communities. CR, a lecturer in Cape Town from Malawi, mentioned: "We are talking about my native community in Malawi where the majority, about 60\%, read and write but not English. They read and write the local language. Now English therefore is like the language for the elite. Not for the majority people or the masses. And for me therefore I see English some extent as a hindrance, therefore as a language, development of economic ( ) political development for the country, because it allows the elite to continue dominate the masses, because the masses couldn't speak English, do not like English. So it's a language of the elite, and to some extent therefore the language of the dominate elite, who kind of oppresses the masses." It is telling that CR finds the use of English "a hindrance" for development work. In fact, the use of English in work among the local people might alienate one from them. English may identify the development worker with the elite, whose motivations might generate skepticism among the local people. The point behind CR's comment is that if skilled migrants want to share their knowledge and skills among their most needy compatriots they have to use the vernacular to establish rapport with them.

A subject who works in the area of literacy development among local people in Africa also mentioned the diverse local languages she needs in order to conduct her work effectively. YV, a professor at Penn State from Cameroon, wrote in an email response: "When working with francophone teachers, I encourage French literacy. If in the future I focus on health literacy, I might consider using pidgin English to reach the Anglophone 
masses in rural communities. If I work with indigenous peoples from my mother's village of origin, I would enlist the support of someone who speaks Lamnso more fluently than I currently do [I lost it while perfecting my standard English!! LOL]." It is clear that YV's beneficiary of her development work is a very multilingual local community. Even among the Anglophone part of Cameroon, she considers pidgin (rather than elite forms of English) a more effective vehicle for literacy instruction. She regrets losing proficiency in some of the languages she needs, such as her mother tongue Lamnso. Ironically, it is the argument that English is the effective language for global development that has made her lose proficiency in the other languages she needs for her contributions. Her comment alerts us to the dangers of the neoliberal ideology. The promotion of English as the portable resource leads to losing proficiency in other languages necessary for development.

For many others, their development work involved interactions with diverse communities beyond their home and host communities. The Nigerian administrator, MA, who earlier focused on petroleum engineering and made his development contribution primarily to Nigeria narrated how his work now went beyond Nigeria or the US. As the administrator of global programs in the same university, he treated his development contribution as going beyond either the sending or the receiving country. Thinking about his English proficiency, he considered it necessary to shuttle in and out of diverse varieties of English to work effectively in these contexts. As we saw above, he considered his multidialectal proficiency an asset for this kind of transnational development work. Similarly, another professor ML (originally from Tanzania) considered her development work as related to neither her host nor home countries. She had chosen to work with women of Sudan. She explained:

My project is in Sudan, what I do, I do migration in Sudan, that's what I work on and I have more ties more connection with the women in the villages in Sudan than in the my father's village, so I don't know. So native to me is not necessarily where I'm coming from but native to me is the people who belong to the same affinity and what have you, so that's how I define it. So I do have those connections, but am I born or raised Sudan? No. It's the connection that I invented and intended to keep.

For this work, ML obviously needs more than her mother tongue or English. What these examples also reveal is that development work for these professionals is not limited to home or host countries.

Many of the subjects also recognized that development needs of their home countries now meant more than interacting with traditionally advanced English-dominant or European countries, as they had to borrow material and intellectual resources from diverse countries. Consider the perspective of CY, a lecturer in Cape Town from Zambia. She said:

So because trading has opened up to Dubai, you know, China, you know, Asian countries, English is insufficient for that kind of economy that is existent there and Zambia is a trader's economy you know. It's a trader's economy or the unemployment is so up for about $90 \%$ so there is no formal employment, so everyone is trading. Trading each other and not trading just internally. Trading across borders or cross border traders so not only are the international languages 
only English, it's Chinese, it's French, and it is Arabic increasingly with the Dubai networks you know opening up. In terms of in the continent it is Portuguese, it is French because we've got the DRC trade ( ) coming in and also trade because we don't have people, commodities who ( ) then learning Shona is useful given their current economic crisis, you know knowing a bit of Tswana is a good thing at the border ( ) you know so those kinds of languages are increasing into the trading economy of Zambia and English is so dominant through the base language but English and ( ) is gonna make for a useful trader you know as opposed to someone who is stuck in there British colonial English proficiency.

$\mathrm{CY}$ recognizes that there are new markets developing for trade for her compatriots. In addition to the new non-western countries deserving attention (such as China and Dubai), she also recognizes the importance of cross-border trade and economic relationships within Africa. For such economic activities, she feels that a repertoire of diverse non-elite languages is an asset for her compatriots. Though many of the subjects did appreciate the English education they had received from their home countries, they also felt that they were "putting all our eggs in one basket" (as LO from Zimbabwe put it). LO's recommendation was "diversify your language portfolio" in recognition of the new and varied opportunities for development beyond the traditionally dominant communities.

Sharing one's skills and knowledge even in host/receiving communities involves interactions with people from diverse countries. Multilingualism is a resource in such contexts. Some of the subjects were engaged in social work among migrants in the host/ migrant communities and expressed that they needed diverse languages beyond English to do perform their development work effectively. We have to also realize that effective development work even in the West involves drawing knowledge from communities beyond dominant western countries. If development work focuses not solely on positivistic orientations to science, but diverse forms of local knowledge, proficiency in vernaculars can certainly help. As we saw above, ML mentioned that her multilingual identity and life history enabled her to draw from alternate forms of knowledge to contest mainstream assumptions. She could perform her dissemination and construction of knowledge in classrooms more creatively and critically because of her multilingual identity and background. The understanding of the knowledge involved in development work for the interviewees is therefore very diverse and inclusive. To tap into local knowledge from a more diverse range of communities for one's development, proficiency in languages beyond English is an asset. Though one might argue that English can provide access to the knowledge of diverse communities, we have to keep in mind the risks and challenges involved in translation.

\section{The sociolinguistics of the migration/development nexus}

The communicative practices in the social life of skilled migrants show a different orientation to languages and competence. I label the orientation emerging from their practice translingual, to contrast with the dominant monolingual orientation of the neoliberal ideology see (Canagarajah 2013 for a detailed discussion of these labels). According to the translingual orientation to competence, languages are always in contact, mutually influence each other, and generate new meanings and forms for communication. In this perspective, it is possible for speakers to engage in a speech event with Englishes of 
diverse varieties or even with diverse languages. Each communicative event can involve more than a single language or dialect, unlike the monolingual orientation which requires a shared code for communicative success. It is this unusual assumption that explains why ET in Bradford says that he adopts his own variety of English with British clients and expects to be understood by them. MN says he and his international colleagues use their own varieties of English, and they can still have a conversation successfully. Their narratives suggest that they are able to achieve intelligibility despite the inherent diversity in communication. MN's testimony suggests that even native speakers ("Britons" as he refers to them) are able to engage with them effectively in appropriate contexts where they are motivated to adopt such a translingual communicative practice.

How is such translingual communication possible? A communicative practice that assumes diversity is based on different practices from those assumed in the monolingual orientation. Consider the clues DB provides:

DB (Zimbabwe, female, researcher in Penn State): We speak that language and may be may be somebody walks in and speaks Afrikaans you start speaking Afrikaans and a conversation can continue in three different languages, somebody speaks Afrikaans and I respond in Zulu and she responds in Tswana and continue talking, nothing unusual there. I understand what he says, she he understands what I ' $m$ saying, I understand what she say and he understands, so we all are engaged in a conversation. And there is nothing abnormal for us.

DB illustrates the linguistic fluidity in the interaction by referring to how "a conversation can continue in three different languages." The fact that such practices are part of her everyday practice is suggested by her repeated mention that it is "nothing unusual" and "nothing abnormal." What makes this conversation in three languages possible is mutual receptive competence. It is possible for each interlocutor to speak in their own language because they all understand each other's languages. Such "receptive multilingualism" is a widespread phenomenon in the context of transnational life see (Braunmüller 2006). This capacity enables what some scholars label a "polyglot dialog" (Posner 1991), where a conversation can take place in multiple languages, with each interlocutor using his/her own language.

Receptive competence in itself is not sufficient to facilitate translingual communication. This form of communication is a collaborative achievement. Both parties in the communication have to achieve intersubjective understanding. In a context where participants assume the existence of diverse and relative language norms, they need the capacity to negotiate norm differences by adopting suitable negotiation strategies. In their narratives, the subjects gave clues as to the strategies they adopt to achieve such intelligibility. To begin with, the subjects expect mutual collaboration. Consider the views of the following two subjects:

GHM (Uganda, female, school administrator in Bristol): I don't feel any tension about my ability to communicate in English and I think that it is sloppy when people say that they do not understand a person due to accent et cetera, as I speak a little of many different languages and try my best to communicate with everybody and expect all to do likewise. 
MA (Nigeria, male, university administrator at Penn State): Probably by paying more attention, just like they have to pay more attention to me as well, it is a two-way street, because of my the combination of Nigerian and British accent and all sorts of things. People had to listen to me more closely to understand what I said OK? With the same token, I had to listen more carefully to them in order to understand them, [... ] It was both ways, so I will, just by paying more attention.

GHM expects her interlocutors to do as she does-i.e., put forward one's best effort to communicate despite differences in languages and proficiencies. It is not the extent of proficiency that matters, but what the interlocutors can do to work with the proficiencies people bring to the interaction. GHM takes language diversity as the norm and expects people to work collaboratively for understanding, regardless of the codes they bring to the interaction. The next subject, MA, labels communication a "two-way street" and thus provides a telling metaphor for translingual practice. If both parties make an effort to understand each other, through such strategies as "paying more attention" and "listen(ing) more carefully," they can succeed in communication despite differences. What our subjects take as necessary for intelligibility are not shared norms but reciprocal pragmatic strategies.

Other subjects shared other strategies they use to achieve intelligibility. TW, a juvenile prison officer in Sheffield from Zimbabwe, said that he succeeds in communication with fellow multilinguals who bring different varieties of English because they adopt mutual attentiveness: "Most people listen intently when they are speaking to each other because they know that this is not our country and we are bound to make mistakes in the way we say some words." Perhaps his fellow multilinguals adopt this attitude because they come with the healthy attitude that they are all using a language that is not "native" to them. They adopt the humility to accept "mistakes" as normal. Therefore, they are not judgemental. WA, an Ethiopian nurse in Seattle, said that she speaks slowly to facilitate intelligibility: "I try to improve and make myself clear what I am saying or I will try to say it slowly and clearly. So that way we can have common understanding." Similarly, WT, an Ethiopian health professional in Seattle, said that he uses "patience and tact" to resolve differences in English varieties in a given interaction. It emerged that rather than relying on homogeneous norms as ensuring success in communication, the subjects focused on pragmatic strategies that would enable them to negotiate the differences in norms.

How did the subjects develop such a competence for translingual communication? To begin with, many subjects mentioned that formal schooling or instruction in language did not help develop such competence. YC, a Ghanaian researcher in Leeds, mentioned how he had been sent to an institution to remedy his English by his British employer after an interview. He goes on to recount the meaninglessness of the experience. As he finished his initial diagnostic assessment sooner than expected, even his examiner pointed out to him that he didn't need that course. It appears that his interviewers had focused on his different accent and assumed that he was unproficient in English. The instruction he was sent to focused on grammatical control, which was not relevant to YC as he was quite proficient grammatically. Another subject, WB (Ethiopian engineer in Seattle), recounted how his communicative needs went beyond grammar and involved higher level professional discourses. The courses he was prescribed by his employer were not useful as they focused on grammatical instruction. 
Since formal instruction for these subjects turned out to be useless, they adopted the practice of learning by themselves through everyday interactions. Such learning through unorthodox methods in uncharted contexts (known also as "learning in the wild") is beginning to be valued in diverse fields beyond applied linguistics. Recently, natural scientists have turned their attention to the ways people are learning scientific knowledge through their own initiatives (Learning in the wild 2010). The narratives in the data make evident the resources that enable such learning. Many subjects recounted that their multilingual socialization in their home countries had developed in them the dispositions to learn through their own initiative in everyday encounters and social practice. OI from Sierra Leon mentioned:

One thing I have realized personally for a while is that I always loved, may be because I grew up in a multilingual society where you always knew there are other languages all around you, and so you had to way of opening up of other things. I have a feeling that we, it is easier for us to translate and become something else and understand. But Americans tend to be so unique, language, so just like one language and sound one way.

It is interesting that OI considers her openness and her ability to "translate" as deriving from her upbringing in her multilingual upbringing. She compares her disposition with that of "Americans"-i.e., presumably native speakers who are also monolingual-and their lack of tolerance. Similarly, AZ from Zambia narrated the rich linguistic ecology she benefited from:

My father is British, so I have to remember that I grew up communicating in English in the house I didn't really need any other language really and then I grew ( ) and Nyanja because of friends and school I grew up and it's like in class I didn't need another language to communicate with formal school work. But it was in informal play and communication that English wasn't enough that's when I learnt Nyanja not because it was one of the subjects at school but because everybody else included both English and Nyanja and Bemba, Tonga and Lozi and what not.

Though AZ learned English in school, which was enough for her educational needs, she had to learn other languages for social interactions. She learned about four other languages by herself in informal contexts of play.

These testimonies unveil the dispositions that facilitated the "learning in the wild" for the subjects. I define these dispositions in terms of Bourdieu (1977) notion of habitus. The social institutions and structures that contextualize their interactions also shape the structures of feelings and dispositions that enable the subjects to engage creatively with multilingual contexts. These dispositions do not foreclose possibilities of further learning and expansion. The dispositions in fact facilitate further learning. My coding of the data generated the following sets of dispositions:

\section{Language attitudes:}

language norms as open to negotiation

languages as mobile semiotic resources

a functional orientation to communication and meaning 


\section{Social values:}

openness to diversity

a sense of voice and locus of enunciation

strong ethic of collaboration

3. Learning strategies:

learning from practice

adaptive skills

use of scaffolding.

Many of these dispositions are illustrated by the narratives quoted above. To begin with, the subjects bring a specific orientation to language. For example, those like GHM insist on the relativity of norms. She expresses that language norms have to be always negotiated for meaning and not taken for granted as shared or homogeneous. The subjects also take languages as mobile resources that are appropriated by people for their own uses in different contexts, leading to the emergence of new norms. They express the right to appropriate English and use it for their own purposes in their own ways. Consider how MN considers it acceptable that his colleagues in his workplace bring their own varieties of English, and he considers it acceptable for them to negotiate their differences without resorting to native speaker norms. They do not consider English as belonging only to one specific community but open to being adopted by others for their purposes. For this reason, they don't focus on normative correctness but the functional ability to "deliver," as the physician from Bradford (ET) put it. The focus on functions motivates them to negotiate language diversity for intelligibility.

These language attitudes are supported by certain social values that prepare the subjects for conducive interpersonal and intercommunity relationships. They are open to diversity. They think of interactions involving diverse language norms, for example, as the norm. It is this value that enables DB to assume that a conversation involving three languages is "nothing abnormal." However, they bring a strong sense of voice, as we see in ET's insistence that he will expect his clients to negotiate his identity and difference with him when they come for service. The subjects thus start from their own locus of enunciation in any communicative interaction. Their language norms and values are treated as resourceful in communication and not dispensable. It is to be expected that they will grant the very same sense of rootedness and voice to their interlocutors. Their interlocutors too would be expected to draw from their locus of enunciation in communicative interactions. What helps them succeed despite their own voices is the third social value our subjects bring: a strong ethic of collaboration. This ethic explains the attitude to communication as a "two-way street," as articulated above by MA. Our subjects are prepared to collaborate with interlocutors in co-constructing intersubjective norms and meanings to achieve communicative success.

The third set of dispositions relates to learning strategies. It is this disposition that makes skilled migrants lifelong learners who are always expanding their repertoires. The subjects bring the disposition of learning from practice. They have the ability to intuit the rules of languages in and through communication. As we saw above, AZ mentioned above how she learnt many languages while playing with her friends. PZ, a Zimbabwean Priest in Leeds, also said: "I am learning different languages at the moment. I am learning Kalanga, Chichewa, Swahili and French which will enable me to 
communicate more with people from different countries. [. . .] I learn the languages by talking to people, I listen when they are speaking in their own languages and I learn that way." The subjects are endowed with the ability to intuit the rules of new norms as they are engaged in conversational interactions. What enables such practice-based learning is also their adaptive capability. Many of our subjects narrated how they get used to new norms and incorporate them into their repertoires. Consider how MA mentioned above that he masters Indian or Chinese English through ongoing interactions during his travel to those countries. LZ (Zimbabwe, male, researcher at Leeds) also pointed out: "Of course sometimes you will find some English accent and dialects difficult to understand but you can always adapt to different situations. But you can always adapt." LZ repeats the word "adapt" to emphasize his learning strategy. In some cases, the subjects treated the social ecology and agents to scaffold their learning. Consider the learning process of $\mathrm{TT}$, as recounted in an email:

TT (Tanzania, male, teacher in Bristol): There will be tensions as English is my fourth language. This means I wouldn't know some words, some pronunciation, and my accent is not like native speakers. I know this and I am learning everyday from my wife, students and colleagues. How do you handle/overcome these differences? I socialise with native speakers of English and at home I communicate in English with my wife and family while learning Creole, my wife's native language, and she learns Kiswahili my native language. And we also read widely.

TT shares how he learns different languages simultaneously. He is using diverse agents-his wife, students, and colleagues-as enablers of his learning. We also see that these practices are complemented by his tolerant language attitude-i.e., an acceptance that his norms will be different from those of native speakers of English.

\section{Reorientating to portable resources}

So, what are the portable resources for skilled migration, professional communication, and development? My study shows not only that it is not one language (i.e., English), as assumed by human-capital perspectives and neoliberal orientations. In fact, these portable resources are not primarily languages. The resource that seems to help our subjects succeed in professional and development contexts are certain dispositions that enable them to treat languages as fluid semiotic resources that need to be constantly renegotiated for situated meanings as one expands one's repertoires for communication. The competence skilled migrants bring is not in individual languages, but in certain dispositions that enable them to shuttle across diverse languages and communities, and acquire newer languages. Their dispositions enable them for language learning that is "lifelong and lifewide" (Duff 2008, p.257).

We have to appreciate the way such dispositions provide a different resource of flexibilization. Neoliberal orientations treat a single language (English) as the convenient way for migrant workers in the knowledge economy to be mobile and successful. The limitation with this approach is that in everyday work and development contexts skilled migrants use multiple English varieties and multiple languages. Neoliberal orientations also underestimate the diversity of English when they put faith on the ability of lingua franca English to solve communication problems in transnational life. 
Translingual dispositions, however, provide a more realistic and efficient way to deal with flexibilization. Such dispositions enable skilled migrants to engage with diversity creatively, expand their repertoires, and achieve communicative success. Rather than assuming homogenous communication as the norm, portable dispositions assume linguistic diversity as ever-present and even enriching and prepare subjects to negotiate them effectively for communication. Therefore, the translingual dispositions are a more constructive and rewarding human capital to develop among knowledge workers worldwide.

The findings from the study show not only a more effective communicative approach, but a more meaningful professional and development relationship. In the scripted monolingual communication favored by neoliberal orientation, what is prioritized is language as a tool for information transfer. Perhaps motivated by the goal of efficiency and short term (or transitory and instantaneous) communication in transnational business relationships, neoliberal orientation separates language from its accompanying cultural and knowledge sources. However, the approach of the skilled migrants, which draws from their identities, values, and local knowledge, offers a different professional and development relationship. When skilled migrants draw from their linguistic repertoires for communication, they are treating language as an ecological resource. Skilled migrants enjoy the potential of informing their work and development efforts with a diverse pool of knowledge, values, and approaches. While monolingualism limits the resources of skilled migrants (as demonstrated in YV's confession that she has lost her mother tongue while developing standard English), translingualism enhances their contribution, as we saw in the examples from ML.

Note also that the portable dispositions of the subjects are not inculcated in formal institutional contexts, but tacitly developed through socialization. Human capital orientations prioritize quantifiable, formally credentialized, and objective skills, ignoring more informal, tacit, and subtle resources of the nature displayed by the interviewees. Scholars of skilled migration are now recognizing the need to foster such tacit competencies and dispositions knowledge workers bring to the new economy. Williams and Balaz (2008), p. 34 note: "Researchers are still coming to terms with this different way of understanding skills, most notably through the notion of competences. Migration research, by and large, has lagged behind this paradigmatic shift." By the notion of "competence," Williams and Baraz refer to the tacit knowledge and dispositoins that workers develop through personal interactions and socialization.

However, we have to be wary of uncritically celebrating tacit knowledge. McElhinny (2012) suggests that the notion of tacit knowledge has also been appropriated by neoliberal ideology to emphasize the lifelong and lifewide learning that has to take place among workers at a personal level. They appreciate the value of such learning, as professions are very unstable and workers cannot be satisfied with formalized training always in the knowledge economy. Tacit learning ensures that workers will always find their own recourse for learning as they shift from place to place and develop a diverse portfolio. Furthermore, the notion of tacit learning also expands the work domain into personal domains and increases the time given to work in one's life. This too is to the benefit of the neoliberal economy. However, we have to appreciate the difference behind the types of dispositions emerging in this study. These dispositions are agentive, critical, and rooted. The tacit knowledge the subjects bring makes them open to 
alternate sources of knowledge and values, and questions the assumptions motivating neoliberal work and development. It is resistant to the narrow knowledge required for corporate productivity in the neoliberal economy.

We have to also add the caveat that multilingualism is not totally new to neoliberal orientations. Scholars now talk of orientations such as total quality management that treats multilingualism as value added for business purposes (Urla 2012). However, this orientation to multilingualism is still influenced by monolingual ideologies and neoliberal thinking. Languages are treated in hierarchical ways, with lingua franca such as English occupying higher status and local languages treated as secondary and situational. Furthermore, the languages are kept separate for scripted interactions, and not allowed to come into contact in the fluid ways they do in translingual practice. In fact, languages are treated as instruments of communication and profit, and not treated in holistic ways as drawing from diverse ecologies, identities, and cultures to reshape work and development. Such scripting and exploitation of languages for profit or remittance purposes prevents professionals from drawing from local knowledge and diversity agentively to enrich work and development. Therefore, such multilingual orientations of neoliberal approaches don't benefit from the radical implications of translingual practice.

The findings from this study don't have to be treated as oppositional to formal education. It is possible to focus on the development of such portable dispositions in schools and workplace training. Such an education will move beyond form, language structure, and native speaker competence, and develop such subtle aspects as language awareness, strategies of negotiation, metalinguistic abilities, and strategic competence. Classrooms or professional training can also focus on developing the conducive dispositions for lifelong and lifewide learning. We must aim to make students and professionals sensitive to the types of language attitudes, social values, and learning strategies that facilitate translingual competence. This approach would require a paradigm shift in language teaching approaches. Focusing on teaching the norms of one language at a time is simply insufficient for the needs of globalization when all of us are required to shuttle between languages and cultures in our everyday life and diversify our portfolios. We have to move to a different orientation that focuses on the dispositions that prepare global professionals to engage with diversity creatively.

\section{Endnotes}

${ }^{\mathrm{a}}$ It is not clear if the communicative proficiencies and resources for unskilled migrants are different. There is anecdotal evidence that unskilled migrants also engage in the translingual practices described in this article and display proficiency in diverse languages and English varieties. However, this needs to be empirically studied. The reason for focusing on skilled migrants in this study is for the importance given it in development circles. The distinction in not being made on linguistic grounds.

${ }^{\mathrm{b}}$ This is a multi-sited qualitative study, funded by the Worldwide Universities Network. I thank the following Co-PI's for their help in collecting data: Adrian Bailey, Leeds University, UK; Frances Giampapa, Bristol University, UK; Margaret Hawkins, University of Wisconsin, USA; Ellen Hurst, University of Cape Town, South Africa; Ahmar Mahboob, University of Sydney, Australia; Paul Roberts, York University, UK; and Sandra Silberstein, University of Washington, USA. 
"I am using "dialects" as an umbrella term to include different varieties of English. Some of the subjects speak varieties recognized in the World Englishes paradigm, as they come from former British colonies (i.e., Ghana, Uganda). Others have their own accents and lexical and grammatical peculiarities, although they don't come from the Outer Circle (i.e., Ethiopia, Congo). Furthermore, these subjects interact with communities in host countries which have display regional or ethnic variation (i.e., Yorkshire dialect, or Black English). To accommodate all this diversity in English in the data, "dialect" is used as a common term. This article, however, doesn't treat such constructs as "dialects" and "varieties" as rigid constructs or stable systems. The translingual orientation treats language diversity as the norm, with new codes and grammars (beyond the traditionally recognized World English varieties or sociolinguistic dialects) constantly evolving in relation to practice.

Competing interests

The author declares that he has no competing interests.

\section{Acknowledgement}

thank the following Co-PI's for their help in collecting data: Adrian Bailey, Leeds University, UK; Frances Giampapa, Bristol University, UK; Margaret Hawkins, University of Wisconsin, USA; Ellen Hurst, University of Cape Town, South Africa; Ahmar Mahboob, University of Sydney, Australia; Paul Roberts, York University, UK; and Sandra Silberstein, University of Washington, USA.

Received: 9 July 2013 Accepted: 9 July 2013

Published: 16 July 2013

\section{References}

2010. Learning in the wild. Nature, 813-814. http://www.nature.com/nature.

Adsera, A, and M Pytlikova. 2010. The role of language in shaping international migration, Evidence from OECD countries 1985-2006. www.cepr.org/meets/wkcn/2/2429/papers/Adserafinal.pdf. (Accessed 24 February 2011).

Bhagwati, J. 1976. Taxing the brain drain, vol. 1: A proposal. Amsterdam: North Holland.

Birks, M, and J Mills. 2011. Grounded theory: A practical guide. London: Sage.

Bleakley, H, and A Chin. 2004. Language skills and earnings: evidence from childhood immigrants. The Review of Economics and Statistics 84(2): 481-496.

Bourdieu, P. 1977. Outline of a theory of practice. Cambridge: CUP.

Braunmüller, K. 2006. On the relevance of receptive multilingualism in a globalised world: theory, history and evidence from today's Scandinavia. University of Groningen: Paper read at the First Conference on Language Contact in Times of Globalization. September $28^{\text {th }}$.

Canagarajah, AS. 2013. Translingual practice: global englishes and cosmopolitan relations. New York: Routledge.

Chiswick, BR, and PW Miller. 1995. The endogeneity between language and earnings. Journal of Labour Economics 13(2): $246-288$

Chiswick, BR, and PW Miller. 2002. Immigrant earnings: Language skills, linguistic concentrations and the business cycle. Journal of Population Economics 15(1): 31-57.

Chiswick, BR, and PW Miller. 2007. The international transferability of immigrants' human capital skills, IZA discussion papers 2670, institute for the study of labor (IZA). ftp://repec.iza.org/RePEc/Discussionpaper/dp2670.pdf. (Accessed 24 February 2011).

Clarke, AE. 2005. Situational analysis: grounded theory after the postmodern turn. Thousand Oaks: Sage.

Duchene, A, and M Heller. 2012. Language in late capitalism. New York: Routledge.

Duff, PA. 2008. Language socialization, higher education, and work. In Language socialization: encyclopedia of language and education, ed. P Duff and N Hornberger, 267-270. Boston: Springer.

Dustmann, C. 1994. Speaking fluency, writing fluency and earnings of migrants. Journal of Population Economics 7: $133-56$.

Dustmann, C, and F Fabbri. 2003. Language proficiency and labour market performance of immigrants in the UK. The Econometrics Journal 113: 695-717.

Dustmann, C, and A van Soest. 2002. Language and the earnings of immigrants. Journal Industrial and Labor Relations Review 55(3): 473-492.

Heller, M, and A Duchene. 2012. Pride and profit: changing discourses of language, capital, and nation-state. In language in late capitalism, 1-22. New York: Routledge.

Kuznetsov, Y. 2006. Diaspora networks and the international migration of skills. Washington, D.C: World Bank

Lorente, B. 2012. The making of "workers of the world": Language and the labor brokerage state. In Language in late capitalism, ed. A Duchene and M Heller, 183-206. New York: Routledge.

Martin, IP. 2012. Diffusion and directions: English language policy in the Philippines. In English in southeast Asia: features, policy and language in use, pp. 189-205, ed. EL Low and A Hashim. John Benjamins Publishing Company.

McElhinny, B. 2012. Silicon valley sociolinguistics? Analyzing language, gender, and communities of practice in the new knowledge economy. In Language in late capitalism, ed. A Duchene and M Heller, 230-260. New York: Routledge.

Mercer, C, B Page, and M Evans. 2008. Development and the African Diaspora. London: Zed Books. 
Piller, I, and J Cho. 2013. Neoliberalism as language policy. Language in Society 42: 23-44. doi:10.1017/ S0047404512000887.

Posner, R. 1991. Der ployglotte dialog. Der Sprachreport 3: 6-10.

Urla, J. 2012. Total quality language revival. In Language in late capitalism, ed. A Duchene and M Heller, 73-92. New York: Routledge.

Williams, AM, and V Balaz. 2008. International migration and knowledge. London \& New York: Routledge.

doi:10.1186/2191-5059-3-8

Cite this article as: Canagarajah: Skilled migration and development: portable communicative resources for transnational work. Multilingual Education 2013 3:8.

Submit your manuscript to a SpringerOpen ${ }^{\circ}$ journal and benefit from:

- Convenient online submission

- Rigorous peer review

- Immediate publication on acceptance

- Open access: articles freely available online

- High visibility within the field

Retaining the copyright to your article 